LUIZ ALBERTO DIB CANONICO

\title{
DETECÇÃO DE PERIODONTOPATÓGENOS DO COMPLEXO VERMELHO EM ATEROMAS DE ARTÉRIAS CORONÁRIAS DE PACIENTES COM DOENÇA CARDIOVASCULAR E PERIODONTITE CRÔNICA
}




\section{Luiz Alberto Dib Canonico}

Detecção de periodontopatógenos do complexo vermelho em ateromas de artérias coronárias de pacientes com doença cardiovascular e periodontite crônica

Tese apresentada à Faculdade de Odontologia da Universidade de São Paulo, para obter o título de Doutor, pelo Programa de PósGraduação em Ciências Odontológicas.

Área de Concentração: Periodontia

Orientador: Prof. Dr. Giuseppe Alexandre Romito

São Paulo

2009 
Canonico, Luiz Alberto Dib

Detecção de periodontopatógenos do complexo vermelho em ateromas de artérias coronárias de pacientes com doença cardiovascular e periodontite crônica / Luiz Alberto Dib Canonico; orientador Giuseppe Alexandre Romito. -- São Paulo, 2009.

56p. : tab., graf.; $30 \mathrm{~cm}$.

Tese (Doutorado - Programa de Pós-Graduação em Ciências Odontológicas. Área de Concentração: Periodontia) -- Faculdade de Odontologia da Universidade de São Paulo.

1. Vasos coronários - Placas de ateroma - Doenças periodontais 2. Doenças cardiovasculares - Complicações 3. Arterioesclerose - Periodontite crônica

AUTORIZO A REPRODUÇÃO E DIVULGAÇÃO TOTAL OU PARCIAL DESTE TRABALHO, POR QUALQUER MEIO CONVENCIONAL OU ELETRÔNICO, PARA FINS DE ESTUDO E PESQUISA, DESDE QUE CITADA A FONTE E COMUNICADA AO AUTOR A REFERÊNCIA DA CITAÇÃO.

São Paulo,

Assinatura:

E-mail: 


\section{FOLHA DE APROVAÇÃO}

Canonico LAD. Detecção de periodontopatógenos do complexo vermelho em ateromas de artérias coronárias de pacientes com doença cardiovascular e periodontite crônica [Tese de Doutorado]. São Paulo: Faculdade de Odontologia da USP; 2009.

São Paulo, / /2009

\section{Banca Examinadora}

1)Prof.(a) Dr.(a)

Titulação:

Julgamento:

Assinatura:

2)Prof.(a) Dr.(a)

Titulação:

Julgamento:

Assinatura:

3)Prof.(a) Dr.(a)

Titulação:

Julgamento:

Assinatura:

4)Prof.(a) Dr.(a)

Titulação:

Julgamento:

Assinatura:

5)Prof.(a) Dr.(a)

Titulação:

Julgamento:

Assinatura: 


\section{DEDICATÓRIA}

"EU SOU O CAMINHO, A VERDADE E A VIDA" Jesus Cristo

A DEUS todo poderoso e JESUS CRISTO, amigos e protetores de todas as horas.

Aos meus pais ALBERTO e NORMA, batalhadores que me deram amor, educação, carinho, incentivo e um porto seguro.

Aos meus irmãos ROSA MARIA e LUIZ GUSTAVO

A minha filha MICHELE minha neta MARIA LUIZA, presentes de DEUS

A minha querida avó NEFA que com 95 anos, sempre com palavras sinceras. 


\section{AGRADECIMENTOS}

"Aquele que perde dinheiro, perde muito; aquele que perde um amigo, perde muito mais. Aquele que perde a fé perde tudo"

Eleanor Roosevelt

Á Faculdade de Odontologia da Universidade de São Paulo - São Paulo na pessoa do seu diretor, Prof. Dr. Carlos de Paula Eduardo, pela estrutura oferecida para esta etapa da minha formação profissional e aos seus funcionários.

Ao meu orientador, mestre e amigo, Prof. Dr. Giuseppe Alexandre Romito, obrigado por tudo, pelos ensinamentos e conselhos nesses anos de convívio. Meus sinceros agradecimentos.

- Prof. Dr. Francisco Emílio Pustiglioni, grande nome da Periodontia Mundial, obrigado por ter aberto as portas da disciplina de Periodontia e acreditar neste trabalho, minha admiração e eterna amizade.

A

os professores da Disciplina de Periodontia da FOUSP, Prof. Dr. Roberto Fraga Moreira Lotufo (in memoriam), Prof. Dr. Giorgio de Micheli, Prof. Dr. Luiz Antônio Pugliesi Alves de Lima, Prof. Dr. Marco Antonio P. Georgetti, 
Prof. Dr. Cláudio Mendes Pannuti, pela dedicação no ensinamento da Periodontia.

os meus colegas de pós graduação em especial a MESTRE em Periodontia, SILVIA LINARD MARCELINO, parceira que me ajudou demais na conclusão deste trabalho.

o Prof. Dr. Francisco Gregori Júnior e equipe, Chefe da Disciplina e do Serviço de Cirurgia Cardíaca da Universidade Estadual de Londrina - UEL, professor e médico competente, homem de sucesso e acima de tudo amigo, humilde, caráter invejável e o melhor adora um rock and roll.

A

os Professores Doutores Fábio Daumas Nunes e Mario Julio Ávila-Campo e equipe pela ajuda e eficiência quando da utilização dos laboratórios.

secretária Márcia Maria dos Santos, pelo profissionalismo e amizade.

À FAPESP, pelo auxilio na pesquisa (protocolo $n^{\circ}$ 04/03199-3)

Agradeço a todos 
Canonico LAD. Detecção de periodontopatógenos do complexo vermelho em ateromas de artérias coronárias de pacientes com doença cardiovascular e periodontite crônica [Tese de Doutorado]. São Paulo: Faculdade de Odontologia da USP; 2009.

\section{RESUMO}

Existe a hipótese, dentro da medicina periodontal, de uma possível relação entre doença periodontal e doenças cardíacas. Talvez a doença periodontal possa agir como um fator desencadeante para o desenvolvimento da doença cardiovascular. Vinte e oito pacientes portadores de aterosclerose e periodontite crônica, submetidos à intervenção cirúrgica de revascularização cardíaca e endarterectomia coronariana, participaram do estudo, cujo objetivo foi avaliar nas placas de ateroma de artérias coronárias a presença dos periodontopatógenos do complexo vermelho: Porphyromonas gingivalis, Tannerella forsythia e Treponema denticola. O DNA genômico foi extraídos das amostras de ateromas e se constatou a presença das bactérias através da reação em cadeia da polimerase (PCR). Detectou-se nas 28 amostras de ateroma: P. gingivalis em $50 \%, T$. forsythia em $7,1 \%$ e $T$. denticola em $3,6 \%$ respectivamente. Estes resultados ajudam a defender a hipótese de que a doença periodontal pode ser um dos muitos fatores envolvidos com 0 desenvolvimento da doença cardiovascular, sendo mais um motivo para ser precocemente diagnosticada, prevenida e tratada.

Palavras-Chaves: Doença Periodontal, Doença Cardiovascular, Aterosclerose, Periodontopatógenos, PCR 
Canonico LAD. Deteccion of periodontopathogens of the red complex in the atheroma of the coronary arteries from patients with cardiovascular disease and chronic periodontitis [Tese de Doutorado]. São Paulo: Faculdade de Odontologia da USP; 2009.

\section{ABSTRACT}

In the field of periodontal medicine there is the hypothesis of a possible connection between periodontal diseases and heart diseases. Maybe the periodontal disease may work as a triggering factor in the development of periodontal of cardiovascular diseases. Twenty-eight patients of atherosclerosis and cronical periodontitis patients were subjected to surgical intervention for cardiac revascularization and coronary endarterectomy, have made part of the study, whose objective was to evaluate the presence of periodontopathogens of the red complex in the atheroma platelets: Porphyromonas gingivalis, Tannerella forsythia and Treponema denticola. Genomic DNA was extracted from atheroma samples, and the presence of bacteria was stated through polymerase chain reaction (PCR). In the 28 samples of atheroma were detected: P. gingivalis at $50 \%$, T. forsythia at $7.1 \%$ and $T$. denticola at $3.6 \%$ respectively. These results help to sponsor the hypothesis that the periodontal disease can be one of several factors involved in the development of cardiovascular disease, being this another reason for its early diagnosis, prevention and treatment.

Keywords: Periodontal Disease, Cardiovascular Disease, Atherosclerosis, Periodontopathogens, PCR 


\section{LISTA DE FIGURAS}

Gráfico 5.1 - Prevalência de bactérias presentes em ateroma ..................... 39

Quadro 4.1 -Bactéria alvo, seqüência dos iniciadores temperatura de anelamento, pares de base e referência ................................. 37 


\section{LISTA DE TABELA}

Tabela 5.1 - Prevalência de bactérias presentes em ateroma 39 


\section{LISTA DE ABREVIATURAS E SIGLAS}

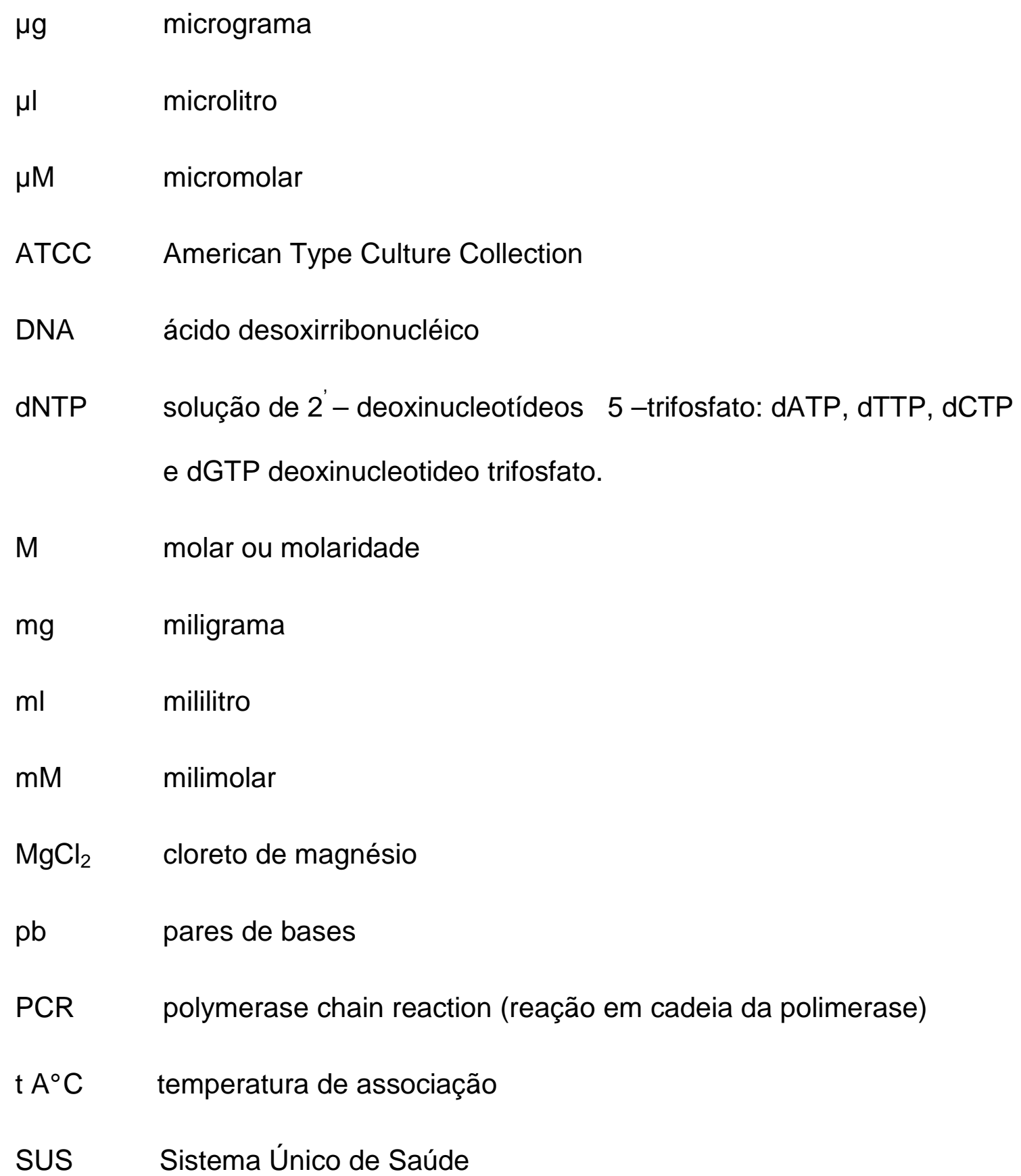




\section{SUMÁRIO}

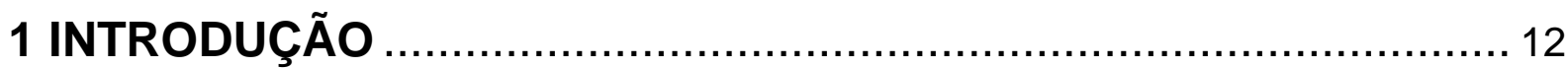

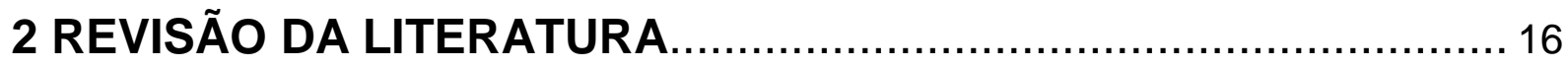

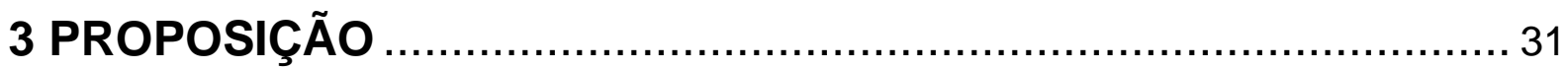

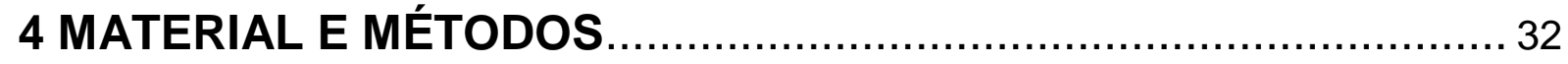

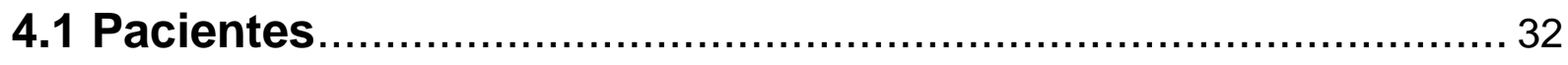

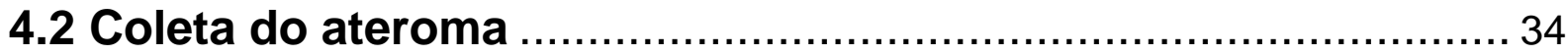

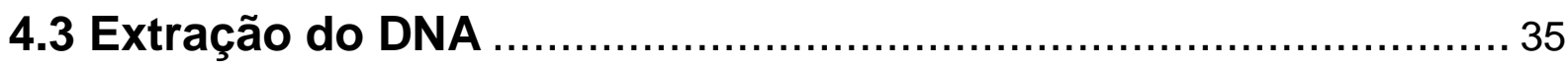

4.4 Detecção bacteriana ...................................................... 36

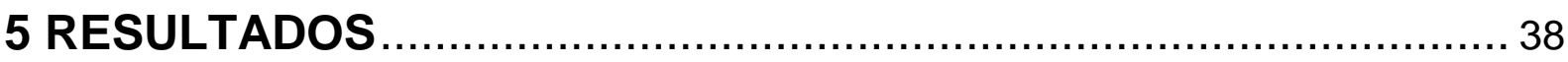

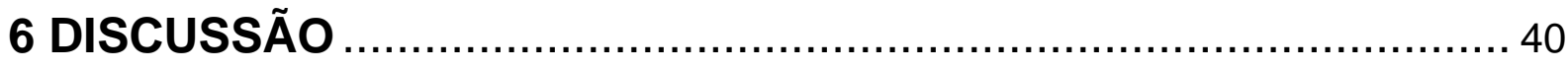

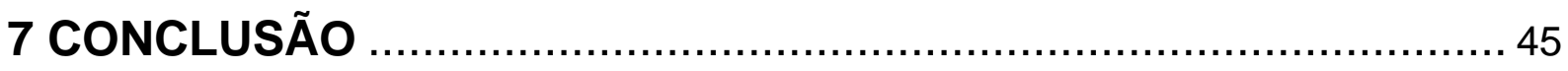

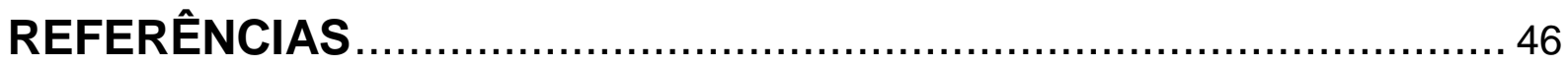

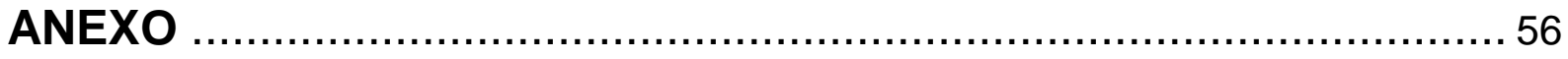




\section{INTRODUÇÃO}

A Medicina Periodontal destaca-se como um importante ramo das Ciências da Saúde (FISCHER, 2005). A doença periodontal pode ter influência na saúde sistêmica de um individuo ou o inverso, por isso, a Medicina e a Odontologia devem estar sempre inter relacionadas.

Desde o final da década de 80 , estudos têm demonstrado uma forte relação entre a doença periodontal e diversas doenças sistêmicas (FOX, 1992; HAYNES; STANDFORD, 2003).

As doenças periodontais são multifatoriais, iniciadas por biofilme bacteriano específico, constituído predominantemente por bactérias gramnegativas anaeróbias (HAFFAJEE; SOCRANSKY, 2000), as quais ativam mecanismos teciduais que levam à produção de uma série de eventos inflamatórios e imunológicos ocasionando a destruição dos tecidos periodontais, além disso, representam a infecção mais comum no ser humano e podem afetar de 5 a $30 \%$ da população adulta entre 25 a 75 anos de idade (BROWN; LÖE, 1993).

Socransky et al. (1998) descreveram as principais bactérias relacionadas com a doença periodontal do adulto como sendo as do complexo vermelho: Porphyromonas gingivalis, Tannerella forsythia e Treponema denticola. Uma alta detecção de patógenos periodontais do complexo vermelho têm sido associada com um aumento no risco ou na severidade de certas alterações sistêmicas, como lesões cardiovasculares (DESVARIEUX et al., 2005; DOGAN et al., 2005), pré-eclampsia (BARAK et al., 2007; CONTRERAS et al., 2006), partos prematuros (HASEGAWA et al., 2003; LIN et al., 2007), 
nascimento de bebês de baixo peso (DASANAYAKE et al., 2001) e diabetes (LALLA et al., 2006; SIMS et al., 2002).

Dentre as doenças cardiovasculares (DCV), a aterosclerose é uma doença das artérias que possui a maior incidência de morbidade e mortalidade. Inicia-se na pré-adolescência, e mesmo na infância, e caracteriza-se pelo desenvolvimento de lesões gordurosas, denominadas placas ateromatosas ou ateroscleróticas, na parede arterial interna (GUYTON, 1992).

As doenças ateroscleróticas aparecem entre as principais causas de mortalidade na maioria dos países desenvolvidos (KINANE; LOWE, 2000). Elas representam uma série de respostas celulares e moleculares altamente específicas, que podem ser descritas como uma doença inflamatória (ROSS, 1999). Mais de $50 \%$ dos pacientes portadores de aterosclerose não apresentam os conhecidos fatores de risco (hipertensão, fumo, hipercolesterolemia e diabetes) e alguns fatores adicionais que predispõem à aterosclerose ainda não foram identificados. A importância da descoberta de mais fatores e de seus mecanismos de ação levaria ao desenvolvimento de novas estratégias terapêuticas que poderiam reduzir a prevalência dessa doença (DIAS, 2002).

A influência negativa das infecções bucais na saúde sistêmica tem sua origem na disseminação dos microorganismos, ou de seus produtos, na corrente sanguínea, o que é chamado de bacteremia. Este fenômeno pode ocorrer após procedimento simples de higiene bucal, procedimentos profissionais de tratamento, que induzem sangramento, ou até mesmo durante a mastigação.Estes freqüentes surtos de bacteremia transitória podem representar riscos no estabelecimento de doenças cardiovasculares em 
determinados pacientes (CONNER et al., 1967; GENCO, 2000; TOLEDO; ROSSA JUNIOR, 1999).

Vários pesquisadores concordam com o fato de que a maioria dos casos de endocardite bacteriana desencadeados por patógenos bucais não tem início nos procedimentos odontológicos, mas nas bacteremias transitórias espontâneas, como as decorrentes da higiene bucal e da mastigação (BAYLISS et al., 1984; CARMONA; DIZ DIOS; SCULLY, 2002).

Lafaurie et al. (2007) avaliou a freqüência de bactérias periodontopatogênicas e outras subgengivais, anaeróbias facultativas ou não, presentes no fluxo sanguíneo de pacientes submetidos a raspagem e alisamento radicular e concluíram que a terapia periodontal por meio da raspagem e alisamento radicular induz bacteremia associada a bactérias anaeróbias, principalmente em pacientes com doença periodontal.

Herzberg e Meyer (1996) mostraram que, na presença da doença periodontal, os microorganismos do biofilme dental podem disseminar-se através da circulação causando infecção do endotélio vascular, contribuindo para a ocorrência da aterosclerose, o que aumenta o risco de isquemia do miocárdio e infarto.

Clínicos e pacientes estão cada vez mais cientes de uma possível associação entre a doença periodontal e doenças cardiovasculares, e do potencial da intervenção periodontal preventiva frente à redução dos riscos para o infarto do miocárdio ou acidentes vasculares cerebrais (PAQUETTE; BRODALA; NICHOLS, 2007). 
Uma projeção feita para o ano de 2020 indica que as doenças cardiovasculares serão responsáveis por cerca de $36 \%$ de todas as mortes no mundo (BRAUNWALD, 1997).

O conhecimento atual ainda é insuficiente para explicar o mecanismo biológico da suposta associação entre doença cardiovascular e doença periodontal, entretanto parece existir certa plausibilidade biológica. 


\section{REVISÃO DA LITERATURA}

Os estudos das inter-relações entre algumas doenças e condições sistêmicas e as doenças periodontais, tem assumido um papel importante e dão evidências de que a doença periodontal pode ser também, um dos fatores de risco para o aparecimento de complicações cardiovascular.

De acordo com os Indicadores de Dados Básicos do Ministério da Saúde (IDB - ministério da saúde) no Brasil, em 2005, a porcentagem de óbitos por doenças cardiovasculares chegou a 46,12\%, computando um total de aproximadamente 85 mil óbitos para todas as faixas etárias e sexo (BRASIL, 2005). Dentre as alterações cardiovasculares, a Aterosclerose é a responsável pela maioria dos casos de infarto do miocárdio e de infarto cerebral, representando a principal causa de óbito nos EUA e Europa Ocidental.

Em uma analise de estudos epidemiológicos que avaliaram a doença periodontal como causa de doenças cardiovasculares feito por Cruz e Nadanovsky (2003), foram identificados 35 estudos por meio de busca manual nos volumes especiais de resumos do periódico Journal of Dental Research; de busca nos bancos de dados eletrônicos MEDLINE, LILACS e ISI; e da inspeção de bibliografias dos artigos identificados. Os critérios de inclusão foram: artigos em qualquer idioma publicados entre 1989 e 2000, que relataram a ausência ou presença de associação entre doenças periodontais e doenças cardiovasculares. As evidências disponíveis ainda são esparsas e suas interpretações são limitadas por potenciais vieses e situação de confusão. Os estudos analisados, tanto separadamente quanto juntos, não fornecem 
evidência epidemiológica convincente para uma associação causal entre doenças periodontais e doenças cardiovasculares. Entretanto, a possibilidade das doenças bucais causarem doenças cardiovasculares ainda não pode ser descartada.

Hujoel et al. (2000), avaliaram o risco de doenças ateroscleróticas coronarianas em pessoas com periodontite, com gengivite e sem doença periodontal. Participação deste estudo 8.032 adultos dentados com idade média de 50 anos, sendo 1.859 indivíduos com doença periodontal, 2.421 com gengivite e 3.752 com saúde periodontal. Durante o período estudado (1982, 1984, 1986, 1987 e 1992) foram medidas as mortes por doença aterosclerótica coronariana, hospitalização por causa idêntica, ou procedimentos de revascularização coronária. Como conclusão, os resultados do estudo não mostraram evidências convincentes de que a periodontite e a gengivite estão associadas à doença cardiovascular.

A luz dos vasos sangüíneos deve ser lisa, permitindo a livre circulação de sangue do coração para todas as partes do corpo. No entanto, com o passar dos anos e associado a vários fatores de risco, pode-se formar, no interior das artérias, placas duras e gordurosas que tornam mais difícil a passagem do sangue para os diferentes órgãos. A progressão da formação e o desenvolvimento dessas placas constituem o processo denominado aterosclerose (GARCIA; HENSHAW; KRALL, 2001).

Aterosclerose é o principal tipo de Arteriosclerose, em função das complicações isquêmicas que podem ocorrer no coração, cérebro, rins, intestino e nas extremidades inferiores (ROSS; GLOMSET, 1976). 
A Aterosclerose humana é um processo crônico, progressivo e sistêmico, caracterizado por respostas inflamatórias e fibroproliferativa da parede arterial, causada por agressões na camada íntima das artérias. Como processo sistêmico, freqüentemente, acomete todos os leitos arteriais incluindo a aorta e seus ramos principais: carótidas, renais, ilíacas e femorais. A hipercolesterolemia, a hipertensão arterial (HA), o diabetes, o tabagismo, as reações imunológicas e inflamatórias, e a suscetibilidade genética individual, figuram entre os fatores de risco para o aparecimento das lesões arteriais (ROSS, 1986; VALLE; BAPTISTA, 1996).

A doença aterosclerótica possuindo períodos de quiescência, alternados com fenômenos agudos, que incluem o infarto do miocárdio, angina (desconforto toráxico tipicamente provocado por esforço ou ansiedade, aliviado pelo repouso e não resultando em necrose do miocárdio), insuficiência cardíaca e a morte (SOUZA; STAICO; SOUZA, 2001).

As placas ateroscleróticas são também denominadas Ateromas, são consideradas estáveis quando a espessura da capa fibrosa é espessa com um núcleo lipídico pequeno. Esta placa provavelmente não se romperá facilmente. Já as placas instáveis apresentam um núcleo lipídico grande e uma capa fibrosa fina, sendo as mais propensas a se romperem e, dessa forma, causarem os acidentes tromboembólicos. A ruptura da capa fibrosa, das placas ateromatosas, é provavelmente provocada por metaloproteinases liberadas por macrófagos ativados por linfócitos T (KAl et al., 1998). Neutrófilos e mastócitos (ativados em pacientes com angina instável) também podem ser importantes para desestabilizar as placas ateromatosas, por meio da liberação de elastases e radicais livres de oxigênio (BIASUCCI et al., 1996; DE SERVI et al., 1991). A 
liberação de elastase e radicais livres, com a hiperativação dos neutrófilos, já foi demonstrado, também, em pacientes com periodontite crônica (FIGUEREDO et al., 1999; GUSTAFSSON; ASMAN, 1996).

O centro das placas de ateroma está associado com um infiltrado celular, no qual estão presentes células musculares lisas e hipertróficas, macrófagos e alguns linfócitos (GARCIA; HENSHAW; KRALL, 2001). Cada vez mais, evidências sugerem que a inflamação na parede do vaso sanguíneo tem um papel essencial no desenvolvimento da aterosclerose (ROSS, 1999). No entanto, o gatilho que inicia e sustenta o processo inflamatório ainda não foi definitivamente identificado. Entre os candidatos ao estímulo das respostas inflamatórias e auto-imunes estão as infecções (EPSTEIN et al., 1999).

Vários trabalhos tem reforçado a relação entre indivíduos com doença periodontal e o aumento do risco para desenvolver aterosclerose (BECK; OFFENBACHER, 2005; KOLLVEIT; ERIKSEN, 2001).

Mackenzie e Millard (1963) investigaram a relação entre diabetes e aterosclerose com a presença de cálculos e perda óssea alveolar. Como resultado deste estudo, $62 \%$ dos pacientes com aterosclerose apresentaram mais perda óssea do que os pacientes saudáveis.

Vários estudos têm sugerido uma possível associação entre as doenças periodontais e a extensão e severidade das doenças cardiovasculares (BECK et al., 1996; DESTEFANO et al., 1993; MATTILA et al., 1989; MATTILA et al., 1993; MATTILA et al., 1995).

Segundo Slots (1998) a busca de informações microbiológicas para determinar a relação entre as doenças periodontais e doenças cardiovasculares, dependeria da capacidade de se evidenciar as mesmas 
bactérias orais no processo aterosclerótico. Dentre as bactérias orais deveriam ser incluídas no grupo de patógenos periodontais as espécies de Aggregatibacter actinomycetemcomitans (Aa), Porphyromonas gingivalis (Pg), Prevotella intermédia (Pi), Tannerella forsythensis (Tf) e Treponema denticola $(T d)$.

A doença periodontal apresenta-se como uma das mais destacadas formas de reservatório bacteriano e de disseminação das bacteremias. Em dois trabalhos realizado por Overholser, Moreillon e Glauser (1987, 1988) com extração de dentes em camundongos com e sem doença periodontal, foi possível observar maior incidência de "surtos de bacteremias" no grupo com doença periodonal (95\%) contra $75 \%$ do grupo com saúde.

O grau de inflamação periodontal é suficiente para desencadear uma resposta inflamatória sistêmica que é evidente com o aumento dos níveis dos marcadores inflamatórios, principalmente a Proteína C-reativa (PCR) (CHEN et al., 2006; PUPIM et al., 2004; RAHMATI et al., 2002).

Uma recente revisão realizada por Paraskevas, Huizinga e Loos (2008) explorou os estudos que mostram um nível elevado da proteína C-reativa (PCR) em pacientes com periodontite. Os critérios de eleição das publicações foram: estudos de caso-controle em humanos (avaliação dos níveis de PCR em pacientes com doença periodontal), estudos longitudinais (avaliando nível da PCR após pelo menos 1 mês de tratamento), avaliação de alta sensibilidade para PCR e pacientes com nenhuma desordem sistêmica (incluindo diabetes, doenças cardiovasculares e/ou aterosclerose). Foram identificados inicialmente 448 estudos e, após checagem das referências, resultou em 18 artigos. A maioria dos estudos mostrou níveis mais elevados da PCR em pacientes com 
periodontite, quando comparados aos controles (sem doença). Os estudos também mostraram níveis de PCR superiores a $2,1 \mathrm{mg} / \mathrm{L}$, em pacientes periodontalmente comprometidos. Seis estudos mostraram a redução significativa dos níveis de PCR após terapia periodontal. E como conclusão, os autores reafirmam a interrelação da doença periodontal com os níveis elevados da proteína C-reativa e apresentam modesta evidência do efeito da terapia peridontal na redução dos níveis sistêmicos da proteína.

Outro marcador inflamatório importante é a Interleucina-6 (IL-6). A elevação do nível sistêmico deste marcador está associada a episódios de angina instável e com quadro clínico de doença cardiovascular. Por alguns autores, esta interleucina é considerada como fator de risco cardiovascular (BIASUCCl et al., 1996; MENDALL et al., 1997).

Loos et al. (2000) realizaram um estudo com o objetivo de mensurar os níveis sistêmicos dos principais marcadores inflamatórios para as doenças cardiovasculares (PCR, IL-6 e contagem de leucócitos), em pacientes com e sem doença periodontal crônica. O estudo contou com 150 pacientes, destes 54 tinham periodontite generalizada, 53 periodontite localizada, e um grupo controle com 43 pacientes com saúde bucal.Foram excluídos do estudo os pacientes que possuíam alguma alteração sistêmica, grávidas e que tivesse sido submetido a extrações dentárias recentemente. Os resultados mostraram uma diferença estatisticamente significante dos níveis de PCR, IL-6 e leucócitos para os pacientes com doença periodontal, quando comparados ao controle. Os autores concluíram que essa elevação dos níveis dos marcadores inflamatórios pode aumentar a atividade inflamatória nas lesões 
ateroscleróticas, com aumento do risco de eventos cardíacos e cerebrovasculares.

Chiu (1999) verificou a presença de periodontopatógenos em carótidas humanas. Neste estudo o autor investigou a presença de múltiplos agentes infecciosos em 33 espécies de carótidas, por meio de imunocorantes com anticorpos específicos. Ao final do estudo foram detectados $63,6 \%$ de Chlamydia pneumoniae (C pneumoniae), 42\% de citomegalovírus, $9 \%$ de vírus do Herpes simples, $42 \%$ de Porphyromonas gingivalis e $12 \%$ de Streptococcus sanguis.

Estudos em animais mostraram que a Porphyromonas gingivalis pode induzir agregação plaquetária, aumentar as lesões ateroscleróticas e acelerar o processo aterosclerótico inicial em ratos, geneticamente modificados (HERZBERG; MEYER, 1996; LALLA et al., 2003; LI et al., 2002). Também foi observado que a Porphyromonas gingivalis pode invadir células endoteliais de artérias coronárias e estar envolvida na imunoregulação do processo aterosclerótico,segundo Choi et al. (2002) e Dorn, Dunn Jr e Progluske-Fox (1999).

Haraszthy et al. (2000) identificaram a presença de periodontopatógenos em placas de ateromas, os autores selecionaram 50 pacientes, com idade média de 69 anos, com estenose na carótida e necessidade de endarterectomia. As amostras das placas, obtidas cirurgicamente, foram acondicionadas em frascos com $10 \mathrm{ml}$ de solução salina, para posterior análise microbiológica. No laboratório foi realizada a técnica de amplificação do DNA bacteriano e a reação em cadeia de polimerase (PCR), para identificação das espécies. O resultado da análise microbiológica mostrou que $80 \%$ das placas 
foram positivas para uma ou mais espécie bacteriana. 38\% foram positivas para Cytomegalovírus humano e 18\% para Chlamydia pneumoniae, 30\% foram positivas para Tannerella forsythensis, 26\% para Porphyromonas gingivalis, $18 \%$ para Aggregatibacter actinomycetemcomtans e 14\% para Prevotella intermédia. Ao final deste estudo, os autores concluíram que a presença de periodontopatógenos, bem como, outros microorganismos infecciosos, nas placas ateroscleróticas, pode ter um papel importante no desenvolvimento e progressão de aterosclerose, levando a uma doença vascular coronariana e outras seqüelas clínicas.

Em outra pesquisa, Haraszthy (2001) examinaram 93 ateromas de carótida obtidos durante endarterectomia em 66 individuos (18 mulheres e 48 homens) da população alemã, com idade variando de 43 a 89 anos. Seguindo a mesma metodologia do estudo anterior, as amostras de carótida foram analisadas pela reação em cadeia de polimerase (PCR) para alguns agentes infecciosos e alguns patógenos periodontais. Como resultado, os autores observaram que $93 \%$ dos ateromas foram positivos para um ou mais microorganismos, sendo que $30 \%$ foram positivos para citomegalovírus, $25 \%$ para vírus Herpes simples e 23\% para Chlamidia pneumoniae. Analisando os patógenos periodontais foi possível observar positividade em $39 \%$ dos ateromas para pelo menos um patógeno,sendo $26 \%$ positivos para Tannerella forsytuhensis, 25\% para o Porphyromonas gingivalis, $13 \%$ para Aggregatibacter actinomycetemcomitans, 16\% para Prevotela intermedia e 2\% para o Campylobacter rectus. Os autores concluíram que a infecção periodontal pode ter papel na aterogênese. 
Stelzel et al. (2002) investigaram biópsias de tecido aórtico quanto à detecção do DNA de periodontopatógenos (Porphyromonas gingivalis e Aggregatibacter actinomycetemcomitans ) pela técnica da reação em cadeia de polimerase. Neste estudo foram selecionadas 26 amostras de aorta,durante os procedimentos de cirurgias cardíacas. O material coletado foi analisado, por meio de PCR, quanto à presença dos periodontopatógenos. Vinte e três das vinte e seis amostras apresentaram DNA bacteriano, sendo encontrado,neste estudo, somente DNA de Porphyromonas gingivalis. Para os autores o resultado indicou uma ligação entre a entrada de patógenos periodontais no sistema vascular e a doença periodontal, apesar de só ter sido encontrado uma das bactérias analisadas.

Dias (2002), analisou microbiologicamente pela técnica da reação em cadeia de polimerase os balões retirados de pacientes submetidos a angioplastias coronarianas e que apresentavam quadro clínico de doença periodonal crônica. Também foram analisadas amostras do biofilme dos sítios periodontalmente comprometidos. O objetivo foi correlacionar os microorganismos bucais presentes nos balões de angioplastias, à presença destes nas amostras intra-orais dos mesmos pacientes. Em relação aos patógenos periodontais, $37,7 \%$ dos 61 balões foram positivos para pelo menos 1 patógeno periodontal. 28,6\% foram positivos para Porphyromonas gingivalis , 8,2\% foram positivos para Aggregatibacter actinomycetemcomitans, 20,4\% foram positivos para Tannerella forsytuhensis , $22,4 \%$ foram positivos para Prevotela intermedia e $24,5 \%$ foram positivos para Campylobacter rectus . Dos 61 pacientes, apenas 20 tiveram amostras intra-orais analisadas quanto à presença dos microorganismos periodontopatogênicos. Após analisar a 
presença de patógenos periodontais nos balões e associar a sua presença nas amostras de biofilme intra-orais, os autores chegaram aos seguintes resultados: o patógeno Porphyromonas gingivalis esteve presente tanto nos balões quanto no biofilme, no mesmo paciente, em $45 \%$ (9) dos casos; para o patógeno Tannerella forsytuhensis esta associação esteve presente em 40\% (8); os patógenos Aggregatibacter actinomycetemcomitans e Prevotela intermedia não tiveram associação estatisticamente significante e para Campylobacter rectus a associação esteve presente em 30\% (6) dos casos. 0 estudo conclui que a presença dos patógenos periodontais nas placas ateroscleróticas exerce um papel importante no início e/ou no desenvolvimento das lesões ateroscleróticas e, por conseguinte, na etiologia de algumas doenças cardiovasculares.

Cairo et al. (2004) avaliou a presença de periodontopatógenos em placas ateromatosas e a presença do DNA das bactérias em bolsas periodontais, nos mesmos pacientes. Foram selecionados um total de 52 pacientes, para a realização de endarterectomia de carótida, sendo divididos em 2 grupos: um grupo teste com 26 pacientes dentados e um grupo controle com 26 pacientes edêntulos. Um completo exame periodontal foi realizado, incluindo exame radiográfico panorâmico, e amostras subgengivais foram coletadas no grupo teste. As amostras subgengivais e as placas ateromatosas, coletadas durante o procedimento cirúrgico, foram analisadas utilizando a técnica de reação em cadeia de polimerase (PCR), com primers específicos para cada espécie bacteriana. Os resultados mostraram que nas 52 amostras coletadas durante a endarterectomia, 12 (7 dendados e 5 edêntulos) foram excluídos por apresentar amplificação negativa de DNA. Nas amostras 
subgengivais de 19 pacientes do grupo teste, Tannerella forsythensis foi encontrado em $79 \%$, Fusobacterium nucleatum em $63 \%$, Prevotella intermédia em 53\%, Porphyromonas gingivalis em $37 \%$ e Aggregatibacter actinomycetemcomitans em $5 \%$ dos casos. Nenhum DNA bacteriano foi encontrado, pela técnica de PCR, nas amostras das placas ateromatosas da carótida, em nenhum grupo de pacientes. Os autores concluíram que a presença de DNA dos periodontopatógenos nas placas ateromatosas não poderam ser confirmadas neste estudo e que nenhuma correlação pôde ser estabelecida entre as espécies bacterianas associadas à doença periodontal e a contribuição destas na formação de placas ateromatosas.

Fiehn et al. (2005) coletaram 79 amostras de placa ateromatosa, removidas da carótida ou da artéria femoral, durante procedimentos cirúrgicos de reconstrução vascular, em pacientes com idade variando de 51 a 89 anos, de ambos os sexos. O material coletado de 52 placas ateromatosas da bifurcação de carótida e 27 da artéria femoral foi meticulosamente preparado para cultivo de $\mathrm{Pg}, \mathrm{Pi}, \mathrm{Cr}, \mathrm{Aa}$, Tf, Streptococos orais e Prevotella nigrescens $(P n)$. Apenas 11 amostras de carótida e 13 de artéria femoral foram utilizadas para a extração de DNA e detecção das espécies bacterianas por meio de PCR. Ao final do estudo,nenhuma bactéria investigada cresceu em meio de cultura. Nas 24 amostras submetidas ao PCR foram detectados DNAs bacterianos de $\mathrm{Pi}$ em 100\%, Pn em 8,3\% e Pg em 4,17\%. Com o estudo concluiu-se que não foi possível isolar as bactérias orais viáveis da placa ateromatosa, mas os dados confirmam que o DNA dos patógenos periodontais pôde ser encontrado nas placas ateromatosas. 
Padilla et al. (2006) selecionaram 12 pacientes com periodontite crônica e diagnóstico clínico de obliteração das extremidades inferiores ou estenose da artéria carótida. Todos os pacientes foram submetidos ao procedimento cirúrgico de endarterectomia, uma semana após o exame periodontal que consistia da verificação da profundidade de sondagem, índice de placa, nível clínico de inserção, sangramento à sondagem e evidência de perda óssea radiográfica. As placas de ateroma foram coletadas e levadas para análise microbiológica, bem como as amostras de biofilme subgengival, das bolsas periodontais, coletadas por meio de cones de papel absorvente estéreis. A análise microbiológica do biofilme subgengival mostrou que em 9 amostras foram observadas associações de duas ou três espécies bacterianas e a $P g$ foi a espécie mais comum. Tf foi isolada em apenas 2 casos e Aa em 7 casos. Já na análise microbiológica das placas ateromatosas foi observado Aa em duas amostras. As demais bactérias não foram identificadas. Apesar da pequena porcentagem de identificação dos periodontopatógenos nas placas ateromatosas, os autores concluíram que a identificação de Aa no biofilme e nas placas dos mesmos pacientes pode indicar o papel dos patógenos periodontais na doença aterosclerótica.

Romano, Barbui e Aimetti (2007), fez um estudo semelhante foi realizado com o objetivo de identificar 5 periodontopatógenos ( $\mathrm{Aa}, \mathrm{Pi}, \mathrm{Pg}, \mathrm{Td}$ e Tf) em bolsas periodontais e em ateromas de carótida, nos mesmos pacientes. O estudo incluiu 21 pacientes com idade variando de 56 a 77 anos (8 mulheres e 13 homens), com pelo menos 12 dentes na boca e diagnóstico de doença periodontal crônica (caracterizada por bolsas periodontais com profundidade de sondagem maior e igual a $5 \mathrm{~mm})$. As amostras subgengivais foram coletadas 
com cone de papel absorvente estéril e as placas ateromatosas foram adquiridas após procedimento cirúrgico de endarterectomia. Dos 21 pacientes, 3 foram excluídos por apresentarem resultado negativo após amplificação do DNA dos ateromas. As amostras de biofilme restantes foram positivas para pelo menos um patógeno periodontal. A prevalência de $T f, P g, P i, T d$ e $A a$, nas amostras de biofilme, foram: $72,22 \%, 61,11 \%, 55,56 \%, 50 \%$ e $33 \%$, respectivamente e nenhum DNA bacteriano foi encontrado nas placas ateromatosas analisadas. Como conclusão, a presença de periodontopatógenos nas placas de ateroma não foi confirmada neste estudo, portanto, nenhuma correlação pode ser feita entre as bactérias periodontais e os microorganismos envolvidos nas lesões ateroscleróticas.

Aimetti, Romano e Nessi (2007) analisou em 33 pacientes a presença de cinco periodontopatógenos $(A a, P i, P g, T f$ e $T d$ ), tanto nos sítios com doença periodontal como nas placas ateroscleróticas coletadas por endarterectomia, nos mesmos pacientes. Os resultados deste estudo mostraram a presença de pelo menos uma das bactérias em todas as amostras periodontais.DNA bacteriano foi encontrado em 31 das 33 amostras de placa aterosclerótica. Entretanto, nenhuma das amostras foi positiva, para a presença de DNA bacteriano dos patógenos periodontais testados.

Em outro estudo Pucar et al. (2007) identificaram bactérias periodontais em amostras de artéria coronária de pacientes com aterosclerose através da PCR. Os resultados demonstraram que nas 15 amostras foram detectadas: $P$. gingivalis, $P$. intermedia, $T$. forsythia e $A$. actinomycetemcomitans. Os autores concluíram que microrganismos 
periodontais podem ter uma associação no desenvolvimento e progressão da aterosclerose.

Elkaïm et al. (2008) investigaram a presença de 20 patógenos periodontais nas lesões ateroscleróticas e em vasos sanguíneos saudáveis, e associaram esta condição aos aspectos clínicos e microbiológicos. Vinte e dois pacientes foram incluídos neste estudo, respeitando os seguintes critérios de inclusão: pelo menos 14 dentes naturais, o paciente não poderia ter sido submetido a tratamento periodontal nos 6 meses prévios ao estudo, não ter feito uso de antibióticos 6 meses antes e não apresentar nenhuma outra alteração sistêmica. Antes do procedimento cirúrgico, foram avaliados os parâmetros clínicos periodontais índice de placa (IP), índice gengival (IG), sangramento sulcular à sondagem (SS), profundidade de sondagem (PS), retração gengival $(R G)$ e perda de inserção $(\mathrm{Pl})$.Todos os pacientes com doença periodontal foram divididos em 2 grupos baseados em 3 critérios: média de PS, média de PI e porcentagem dos sítios com PS _ 4mm. 11 pacientes com média de PS das bolsas $<3 \mathrm{~mm}$, PI $<4 \mathrm{~mm}$ e porcentagem de sítios com PS _ 4mm menor que $20 \%$, foram incluídos no grupo periodontite crônica moderada generalizada. Os 11 pacientes restantes que apresentaram média de PS > 3mm, média de PI > 4mm e porcentagem de sítios com PS $4 \mathrm{~mm}$ maior que 20\%, foram incluídos no grupo periodontite crônica severa generalizada. As amostras bacterianas subgengivais foram coletas das 4 bolsas mais profundas de cada paciente, utilizando cones de papel absorvente para posterior extração de DNA. Durante a cirurgia de ponte de safena, realizada um dia após o exame periodontal, foram coletadas placas de ateromas, amostras da camada interna das artérias mamárias saudáveis e 
amostras das veias safenadas, para em seguida ser feita a análise microbiológica. Com relação às amostras periodontais, os resultados mostraram que 16 das 20 espécies bacterianas analisadas foram mais prevalentes no grupo com periodontite severa. Porphyromonas gingivalis e Fusobacterium nucleatum foram as bactérias detectadas em maiores níveis em ambos os grupos. Com relação às amostras vasculares, comparando os grupos, não houve diferença estatística significante em relação a prevalência de alguma das 20 espécies nas artérias mamárias.Diferenças significantes apareceram em 9 das 20 bactérias nas veias safenadas e para a prevalência de Campylobacter rectus e Eikenella corrodens nas placas de ateromas. Foi nítida a maior prevalência de bactérias no grupo com periodontite severa quando comparada ao grupo com periodontite moderada. Os autores concluíram que a presença dos patógenos periodontais nas placas aterosclerótica 31 e nos vasos aparentemente saudáveis, reflete o alto nível de bacteremia, levando a infecção das células endoteliais.

Mesmo diante da vasta literatura apresentada mostrando a presença do DNA bacteriano em placas ateromatosas, a sua contribuição para o início e progressão da doença aterosclerótica ainda precisa ser comprovada. 


\section{PROPOSIÇÃO}

Este estudo teve como proposição avaliar a presença de bactérias do complexo vermelho: Porphyromonas gingivalis, Tannerella forsythia e Treponema denticola, nas amostras de ateroma provenientes da artéria coronária através de endarterectomia coronariana de pacientes com doença cardiovascular e periodontite crônica. 


\section{MATERIAL E MÉTODOS}

O protocolo de pesquisa e o termo de Consentimento Livre e Esclarecido foram submetidos e aprovados pelo Comitê de Ética da Faculdade de Odontologia da Universidade de São Paulo (Anexo A). O paciente ou responsável autorizou sua participação ao assinar o termo de Consentimento.

\subsection{Seleção da amostra}

Foram selecionados do SUS, 28 pacientes (22 homens e seis mulheres), diagnosticados após o exame de cateterismo e diagnóstico de Doença Aterosclerótica Coronariana Obstrutiva (DACO), tal doença é caracterizada por um quadro clínico de estenose arterial maior ou igual a 70\% de obstrução da luz do canal e isquemia evidenciada e periodontite crônica, com média de idade de 61 anos, que seriam submetidos à cirurgia de endartectomia e revascularização coronariana no Hospital Evangélico da Cidade de Londrina, Paraná, no período de março de 2005 a março de 2007. Antes da cirurgia cardíaca, os pacientes foram submetidos a anamnese, exame clínico periodontal, com a realização de um periograma, de acordo com a disciplina de Periodontia da Faculdade de Odontologia da Universidade de São Paulo.

Foram considerados critérios de inclusão: não deveriam ter sido submetidos à antibioticoterapia, nem a tratamento periodontal nos três últimos 
meses prévios à realização da cirurgia. Possuírem, no mínimo, seis dentes na cavidade bucal, e não serem diabéticos. Os pacientes portadores de periodontite crônica apresentavam pela perda de inserção $\geq 5 \mathrm{~mm}$ em $30 \%$ dos dentes presentes (TONETTI; CLAFFEY, 2005).

Um único examinador treinado e experiente, através do coeficiente de correlação intra-classe, realizou todos os exames clínicos no centro de Hemodinâmica do Hospital, em uma sala de preparação pré-operatória, sob a condição de iluminação (Luz branca ambiente) e posição (cama de repouso reclinável) adequadas para o exame. Um auxiliar odontológico foi responsável pela anotação dos dados na ficha.

Utilizando um espelho clínico plano ${ }^{1}$, e uma sonda milimetrada manual $^{2}$, os sulcos/bolsas foram examinados em seis sítios por dente (faces mésio-lingual, lingual, distolingual, mésio-vestibular, vestibular e distovestibular) em todos os dentes permanentes.

Os seguintes parâmetros clínicos foram registrados:

1. Profundidade clínica de sondagem (PCS): distância (mm) compreendida entre a margem gengival e o fundo do sulco gengival ou da bolsa periodontal.

2. Distância da linha esmalte-cemento à margem gengival (LEC-MG): distância $(\mathrm{mm})$ que vai da linha esmalte-cemento à margem gengival. Se a LEC estivesse localizada apicalmente à margem gengival, o parâmetro receberia um valor negativo.

\footnotetext{
Espelho $\mathrm{n}^{\circ}$ \#5, Hu Friedy, Chicago, IL, USA

2 PCPUNC - 15, Hu Friedy, Chicago, IL, USA
} 
3. Nível clínico de inserção $(\mathrm{NCl})$ : é o valor correspondente à soma dos valores de PCS e LEC-MG ${ }^{3}$.

Após todos os procedimentos iniciais, os pacientes ou responsáveis autorizarão sua participação ao assinar o Termo de Consentimento Livre e Esclarecido.

\subsection{Coleta do ateroma}

As placas de ateroma das artérias coronárias foram coletadas através de um procedimento denominado endarterectomia coronariana. A endarterectomia é realizada nos casos em que o leito distal coronariano é totalmente comprometido pela arteriosclerose, o cirurgião ira remover toda a placa arteriosclerotica (incluindo alguns ramos) na sua totalidade através da incisão inicialmente praticada na artéria coronária a ser revascularizada. Geralmente obtem-se um fragmento único que nada mais é que o interior do vaso coronariano, contendo intima e parte média juntamente, evidentemente com toda a placa arteriosclerotica.Em seguida é realizada a revascularização do miocárdio.

O procedimento cirúrgico de endarterectomia coronariana foi realizada pelo cirurgião cardíaco Prof. Dr. Francisco Gregori Júnior e equipe da Universidade Estadual de Londrina - Paraná. Essas amostras foram armazenadas imediatamente em tubos estéreis com $5 \mathrm{ml}$ de RNAlater ${ }^{4}$,

\footnotetext{
$\mathrm{NCl}=\mathrm{PCS}+($ LEC-MG)

${ }^{4}$ Ambion, Apllied Biosystem, Foster CT, USA
} 
acondicionados em um congelador a $-20^{\circ} \mathrm{C}$ e transferi dos ao Laboratório de Patologia Molecular da Faculdade de Odontologia da Universidade de São Paulo, para o processamento.

\subsection{Extração do DNA}

\section{Método de extração com digestão enzimática:}

Aproximadamente $100 \mathrm{mg}$ de tecido foram utilizados para a extração do DNA que foi obtido através do Kit de Extração para Tecido ChargeSwitch ${ }^{5}$ gDNA Mini Tissue Kit de acordo com as instruções do fabricante.

O protocolo para este método de extração de DNA foi baseado no método descrito por Isola et al. (1994).

Serão adicionados aos tubos $400 \mu \mathrm{l}$ de tampão de lise ( $\mathrm{NaCl} 1 \mathrm{M}$; Tris$\mathrm{HCl}$ pH 8,0 1M; EDTA 0,5M pH8, 0; SDS 10\%) estéril e proteinase $\mathrm{K}$ na concentração final de $500 \mu \mathrm{g} / \mathrm{ml}$. Os tubos serão mantidos a $5^{\circ} \mathrm{C}$ em banho maria por 3 dias até a completa dissolução do tecido. Serão adicionados $30 \mu \mathrm{l}$ de proteinase $\mathrm{K}$ a $250 \mu \mathrm{g} / \mathrm{ml}$ em intervalos de 24 horas, e os tubos serão invertidos uma vez ao dia. A enzima será inativada por aquecimento a $95^{\circ} \mathrm{C}$ durante 10 minutos. O DNA será purificado utilizando-se $1 \mathrm{ml}$ de solução de fenol saturado e tamponado $(\mathrm{pH} 8,0)$ e os tubos homogeneizados e em seguida centrifugados a $850 \mathrm{xg}$ por 20 minutos, à TA, quando o sobrenadante será transferido para outro tubo semelhante. Será então acrescentado $1 \mathrm{ml}$ de solução de fenol: clorofórmio: álcool isoamílico (25:24:1) repetindo-se então o

\footnotetext{
${ }^{5}$ Invitrogen do Brasil, LTDA, São Paulo, São Paulo, Brazil.
} 
mesmo processo de homogeneização e centrifugação e por fim $1 \mathrm{ml}$ de clorofórmio:álcool isoamílico (24:1). O sobrenadante final será transferido para outro tubo onde será feita a precipitação do DNA adicionando-se etanol absoluto gelado (2 a 3x o volume do sobrenadante) e acetato da amônia 7M (1/10 do volume do sobrenadante) que permanecera a $-20^{\circ} \mathrm{C}$ por 18 horas. Será realizada centrifugação a $18.300 \mathrm{xg}$ por 20 minutos, a $4^{\circ} \mathrm{C}$, e o precipitado obtido será lavado com etanol a $70 \%$. Após evaporação do etanol a

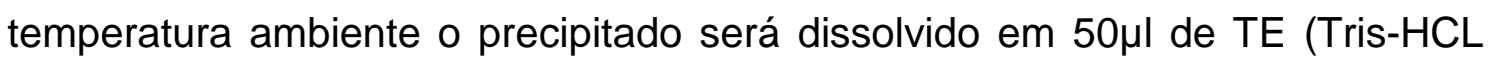
$10 \mathrm{mM} \mathrm{pH} 7,4$ e EDTA $1 \mathrm{mM}$ pH8,0) e mantido a $4^{\circ} \mathrm{C}$ até a quantificação.

\subsection{Detecção Bacteriana por PCR}

As amostras de DNA foram amplificadas pela técnica da PCR utilizando-se iniciadores específicos baseados na seqüência do gene $16 \mathrm{~S}$ rRNA, sintetizadas para Porphyromonas gingivalis, Tannerella forsythia eTreponema denticola, pela Invitrogen ${ }^{5}$ conforme Ashimoto et al. (1996). As amplificações foram realizadas em volume final de $25 \mu \mathrm{L}$ contendo $2,5 \mu \mathrm{l}$ de 10 X PCR buffer, ${ }^{5} 1,0 \mu \mathrm{l}$ of $\mathrm{MgCl}_{2}(50 \mathrm{mM}),{ }^{5} 1,0 \mu \mathrm{l}$ de dNTP mix $(0,2 \mathrm{mM}),{ }^{5} 1,0 \mu \mathrm{l}$ de cada iniciador específico $(0,4 \mathrm{M}),{ }^{5} 0,25 \mu \mathrm{l}$ Taq Platinum DNA polymerase $(0,5 U),{ }^{5}$ e $2 \mu \mathrm{l}$ de DNA das amostras. A reação de amplificação foi realizada em um termociclador ${ }^{6}$ programado para $94^{\circ} \mathrm{C}$ por cinco minutos, 30 ciclos de $94{ }^{\circ} \mathrm{C}$

\footnotetext{
5 Invitrogen do Brasil, LTDA, São Paulo, São Paulo, Brazil.
} 
por 30 segundos, temperatura de anelamento adequada para cada par de iniciadores (Quadro 4.1) por 30 segundos; $72^{\circ} \mathrm{C}$ por 30 segundos e $72{ }^{\circ} \mathrm{C}$ por 5 minutos para a extensão final do DNA.

Os controles positivos foram DNA de cultura pura de bactérias: Porphyromonas gingivalis ATCC 33277, Tannerella forsythia ATCC 43037, Treponema denticola ATCC 33520. O controle negativo foi composto por todos os reagentes presentes na reação e isento do DNA genômico.

O produto de amplificação $(10 \mu \mathrm{l})$ foi observado por eletroforese (70 V por 2,5 horas) em gel de agarose $2 \%$, e corado com brometo de etídio a 0,5 $\mu \mathrm{g} / \mathrm{ml}$ e fotografado sob um transluminador de luz ultravioleta ${ }^{7}$. Como marcador molecular foi usado 1-kb plus DNA ladder ${ }^{5}$.

\begin{tabular}{|c|c|c|c|c|}
\hline Bactéria alvo & Sequência dos Iniciadores (5' --- 3') & $\begin{array}{c}\text { Temperatura } \\
\text { de } \\
\text { anelamento }\end{array}$ & $\begin{array}{l}\text { Amplificação } \\
(\mathrm{pb})\end{array}$ & Referência \\
\hline $\begin{array}{l}\text { Universal Primers } \\
16 \text { S rRNA }\end{array}$ & $\begin{array}{l}\text { AGA GTT TGA TCC TGG CTC AG } \\
\text { CAA TAC TCG TAT CGC CCG TTA TTC }\end{array}$ & $60^{\circ} \mathrm{C}$ & 1500 & $\begin{array}{l}\text { Amano et al. } \\
(1999)\end{array}$ \\
\hline P. gingivalis & $\begin{array}{l}\text { AGG CAG CTT GCC ATA CTG CG } \\
\text { ACT GTT AGC AAC TAC CGA TGT }\end{array}$ & $60^{\circ} \mathrm{C}$ & 404 & $\begin{array}{l}\text { Ashimoto et al. } \\
\qquad(1996)\end{array}$ \\
\hline T. forsythia & $\begin{array}{l}\text { GCC TAT GTA ACC TGC CCG CA } \\
\text { TGC TTC AGT GTC AGT TAT ACC T }\end{array}$ & $60^{\circ} \mathrm{C}$ & 641 & $\begin{array}{l}\text { Ashimoto et al } \\
\qquad(1996)\end{array}$ \\
\hline T. denticola & $\begin{array}{l}\text { TAA TAC CGA ATG TGC TCA TTT ACA T } \\
\text { TCA AAG AAG CAT TCC CTC TTC TTC TTA }\end{array}$ & $55^{\circ} \mathrm{C}$ & 316 & $\begin{array}{l}\text { Ashimoto et al. } \\
\text { (1996) }\end{array}$ \\
\hline
\end{tabular}

Quadro 4.1 - Bactéria alvo, sequência dos primers, temperatura de anelamento, pares de base e referência

\footnotetext{
6 Perkin Elmer, Gene Amp PCR System 9700, Norwalk, CT, USA
}

7 Fotodyne, Inc Hartland, WI 


\section{RESULTADOS}

Participaram deste estudo 28 pacientes sendo 22 homens (77\%) e 6 mulheres (23\%) com idade média de 61 anos, portadores de doença cardiovascular e periodontite crônica. O DNA das amostras de ateroma foi amplificado com primers universais. Todos os controles positivos apresentaram a amplificação esperada para os iniciadores específicos.

A detecção das taxas de espécies bacterianas nas placas de ateromas foi realizada por PCR e descritas na tabela 5.1 e gráfico 5.1. A prevalência de periodontopatógenos do complexo vermelho no ateroma foi de $50 \%$ para $P$. gingivalis (14 placas), 7,1\% para $T$. forsythia (duas placas) e apenas $3,6 \%$ para T. denticola (uma placa). 
Tabela 5.1 - Prevalência de bactérias presentes em ateroma

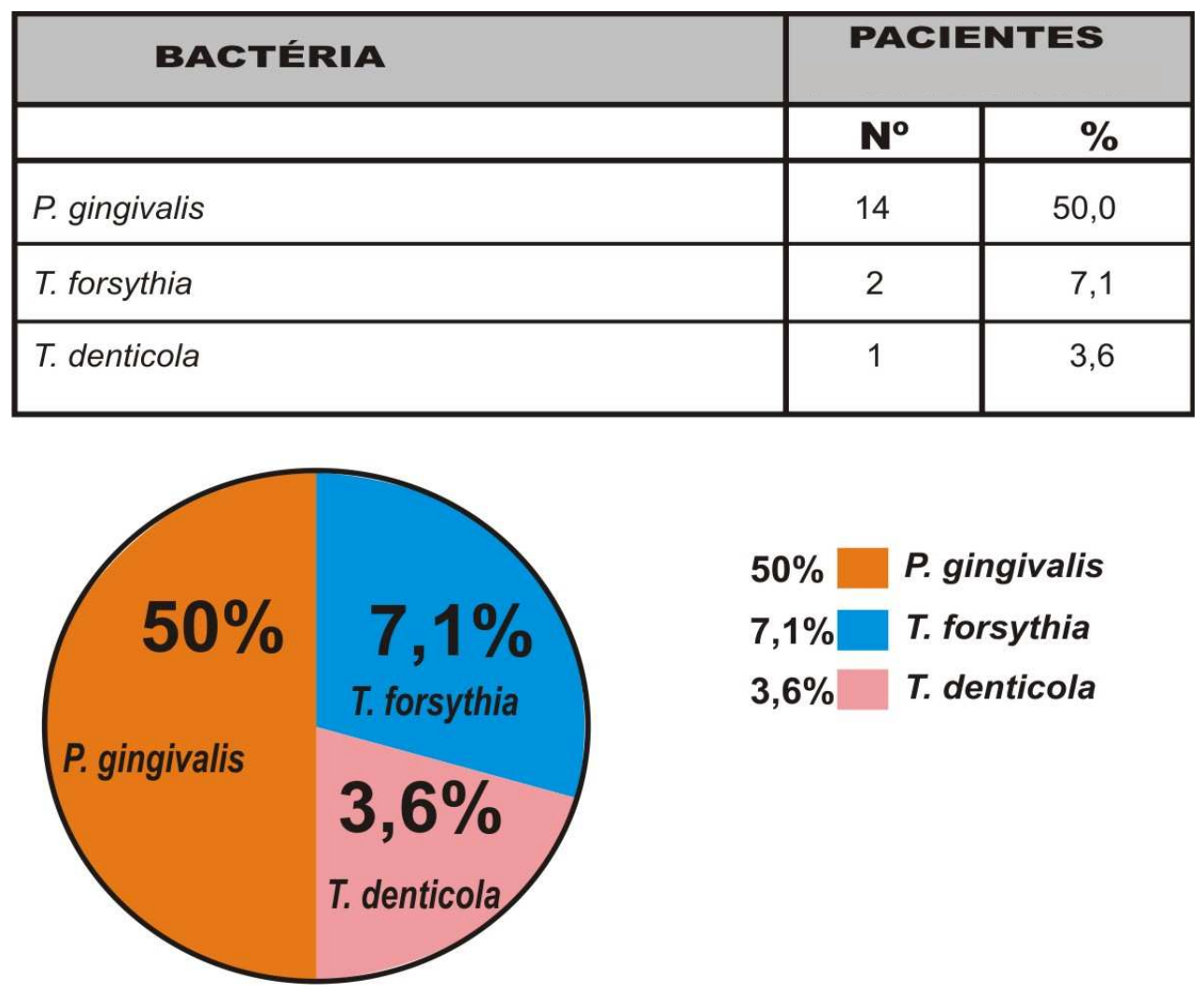

Gráfico 5.1 - Prevalência de bactérias presentes em ateroma 


\section{DISCUSSÃO}

Várias pesquisas têm sugerido uma possível associação entre as doenças periodontais e a extensão e severidade das doenças cardiovasculares (BECK et al., 1996; DESTEFANO et al., 1993; MATTILA et al., 1989; MATTILA et al., 1993; MATTILA et al., 1995). Entretanto, uma completa evidência ainda não foi estabelecida neste campo, principalmente, porque outros estudos que questionam esta associação têm sido publicados nos últimos anos (HUJOEL et et al., 2000, 2001, 2002; ROMANO; BARBUI; AIMETTI, 2007).

O que se observa é que a ligação entre os dois processos imunoinflamatórios, a doença periodontal e aterosclerose, permanece como um tópico controverso, tendo a relação de causalidade como ponto principal, destacando qual o real significado sistêmico da infecção periodontal. Recentemente, alguns estudos não dão suporte a esta associação, afirmando que são necessários estudos longitudinais mais bem controlados, que envolvam populações mais homogêneas e com análises microbiológicas mais específicas para os patógenos periodontais (KHADER; ALBASHAIREH; ALOMARI, 2004; NAKIB et al., 2004).

Mecanismos biológicos plausíveis para explicar esta relação foram desenvolvidos. Mediadores da doença inflamatória bucal poderiam entrar na circulação sanguínea por meio do tecido gengival altamente vascularizado, aderindo na placa ateromatosa e desencadeando uma inflamação com ruptura desta placa, formando um coágulo que impede a circulação sanguínea e causa um infarto (BECK et al.,1998). 
A etiologia da doença cardiovascular e da doença periodontal é multifatorial e, na literatura, encontramos os chamados fatores de risco clássicos que em muitos casos são os mesmos como: idade avançada, gênero masculino, tabagismo, diabetes e baixa condição socioeconômica. Mas, alguns trabalhos epidemiológicos mostraram pacientes com doença cardiovascular que não apresentavam nenhum destes fatores considerados de risco (HARASZTHY et al., 2000). A Academia Americana de Periodontologia considera a doença periodontal um fator que pode contribuir na etiopatogenia da doença cardiovascular, sendo comparável a fatores de risco como tabagismo, diabetes, hipertensão e alto teor de triglicérides (SCANNAPIECO, 1998).

Estudos de Joshipura et al. (2003), Kozarov et al. (2006), Lindsberg e Grau (2003), Page (1998) e Pussinen e Mattila (2004) têm mostrado a doença periodontal como um fator de risco para o desenvolvimento de outras condições sistêmicas e interferindo no curso da doença periodontal como fatores modificadores.

Quanto à identificação de patógenos periodontais como, $P$. gingivalis, T. forsythia e T. denticola em placas de ateromas pela PCR, neste estudo é importante considerar que, a detecção ocorre somente pela presença do DNA bacteriano e não pelas células bacterianas viáveis, representativas de uma espécie patogênica periodontal. Portanto, é possível que apenas algumas seqüências de ácidos nucléicos de uma célula bacteriana degradada estejam acumuladas em ateromas que ocluem as artérias, sem produzir injúrias no endotélio (HARASZTHY et al., 2000). 
Socransky, Smith e Haffajee (2002) descreveram que os principais agentes etiológicos considerados da periodontite crônica são os microrganismos do complexo vermelho: $P$. gingivalis, $T$. forsythia e $T$. denticola. Em nosso estudo, a prevalência destes microrganismos, apresentou uma alta taxa (P. gingivalis 50,0\% - 14 pacientes, $T$. forsythia 7,1\% - 02 pacientes e $T$. denticola $3,6 \%$ - 01 paciente). A presença de $P$. gingivalis em ateromas de pacientes com periodontite em $50 \%$ dos casos está de acordo com dados mostrados de Ishihara et al. (2004) e Pucar et al. (2007) que demonstraram ser estatisticamente significante a presença de $P$. gingivalis em amostras de placa de artérias coronárias. Esta bactéria é capaz de invadir células endoteliais, podendo levar ao acúmulo de plaquetas e fibrina dentro dos vasos cardíacos (DESHPANDE; KHAN; GENCO, 1998), sendo este, um achado importante.

As placas mais profundas do ateroma, que possuem uma baixa tensão de oxigênio, proporcionam o crescimento de anaeróbios. Estas considerações conduzem a hipótese de que os patógenos periodontais anaeróbios podem ser importantes na patogenia do ateroma, não somente durante a sua iniciação, como também, durante a progressão da doença cardíaca. (FIEHN et al., 2005).

A grande dificuldade nos estudos que relacionam periodontopatógenos com aterosclerose é estabelecer se as bactérias são residentes ou transitórias, o que poderia determinar as diferenças nas taxas de detecção em vários estudos (ISHIHARA et al., 2004; TAYLOR-ROBINSON et al., 2002).

Nossos resultados estão de acordo com Ishihara et al. (2004) e Padilla et al. (2006) que detectaram a presença de $P$. gingivalis e $T$. forsythia em diferentes taxas. A presença T. denticola em 3,6\% das amostras é inferior aos dados de Ishihara et al. (2004) e Okuda et al. (2001) que detectaram este 
microrganismo em $23,1 \%$ e $29,4 \%$ dos ateromas avaliados. Esta diferença na taxa de detecção poderia estar associada à existência bactérias residentes ou transitórias, ocorrência impossível de ser estabelecida.

Em complemento, nossos resultados são consistentes com aqueles previamente relatados por Pucar et al. (2007) que detectaram a presença de $P$. gingivalis em $53,3 \%$ e $T$. forsythia em $13,3 \%$ das placas de ateroma. Similarmente, Haraszthy et al. (2000) detectaram T. forsythia em $30 \%$ e $P$. gingivalis em $26 \%$ das placas de ateroma estudadas. Esses achados representam certa evidência de que patógenos periodontais podem entrar na circulação, causando uma bacteriemia transitória, e podem se alojar nas paredes das artérias.

O estudo de Beck et al. (1996) enfatiza que a periodontite é uma infecção crônica onde se geram níveis sistêmicos elevados de fatores de risco, tais como a proteína C-reativa, fibrinogênio e citocinas (IL-1ß, II-6, TNF- $\alpha$ ). Esses fatores quando elevados podem aumentar a atividade inflamatória nas lesões ateroscleróticas, aumentando potencialmente o risco dos eventos cardíacos. Embora na literatura mencionem-se diferenças na ocorrência de bactérias periodontopatogênicas em ateromas, certamente estas diferenças podem ser explicadas pelas diferentes populações estudadas, espécies microbianas subgengivais e a resposta imunológica (AIMETTI; ROMANO; NESSI, 2007).

O método de análise microbiológica por meio de amplificação do DNA, pela reação em cadeia de polimerase, foi escolhido devido ao fato deste teste ser o mais sensível de todos, além de ser mais simples e com resultados mais rápidos, quando comparado aos métodos de microscopia, cultura e sondas de 
DNA (LOESCHE, 1992; WAHLFORS et al.,1995; ZAMBOR; HARASZTHY, 1995).

Os nossos resultados podem ajudar a reforçar a tese, de que a doença periodontal através dos agentes bacterianos, pode sim ser considerada um dos fatores de risco para o desenvolvimento da doença cardiovascular.

É importante ressaltar, como mostrado por D'Aiuto et al. (2004) o efeito sistêmico da terapia periodontal básica (raspagem e alisamento radicular) é suficiente para reduzir de forma significante os níveis sistêmicos da proteína Creativa (PCR) e da Interleucina-6 (IL-6), principais marcadores inflamatórios das doenças cardiovasculares.

Portanto, os pacientes devem ser orientados sobre os riscos da doença periodontal, que além de poder levar à perda do elemento dental, pode contribuir para o aparecimento ou agravamento de doenças sistêmicas, como é o caso da doença cardiovascular. 


\section{CONCLUSÃO}

Dentro dos limites deste estudo, pôde-se concluir que:

Foram encontrados, nas amostras de ateroma analisadas, através da técnica da PCR, periodontopatógenos do complexo vermelho. Em 50\% das amostras encontrou-se a presença de $P$. gingivalis, em $7.1 \%$ a presença de T. forsythia e em 3.6\% das amostras, a presença de T. denticola. 


\section{REFERÊNCIAS ${ }^{1}$}

Aimetti M, Romano F, Nessi F. Microbiologic analysis of periodontal pockets and carotid atheromatous plaques in advanced chronic periodontitis patients. $J$ Periodontol 2007;78(9):1718-23.

Amano A, Nakagawa I, Kataoka K, Morisakl I, Hamada S. Distribution of Porphyromonas gingivalis strains with fimA genotypes in periodontitis patients. J Clin Microbiol 1999;37(5):1426-30.

Ashimoto A, Chen C, Bakker I, Slots J. Polymerase chain reaction detection of 8 putative periodontal pathogens in subgingival plaque of gingivitis and advanced periodontitis lesions. Oral Microbiol Immunol. 1996;11(4):266-73.

Bayliss R, Clarke C, Oakley C, Somerville W, Whitfield AG. The teeth and infective endocarditis. Brit Heart J 1984;50(6):506-12.

Barak S, Oettinger-Barak O, Machtei EE, Sprecher H, Ohel G. Evidence of periopathogenic microorganisms in placentas of women with preeclampsia. J Periodontol 2007;78(4):670-6.

Beck J, Garcia R, Heiss G, Vokonas PS, Offenbacher S. Periodontal disease and cardiovascular disease. J Periodontol 1996; 67(10 Suppl):1123-37.

Beck JD, Offenbacher S. Systemic effects of periodontitis: Epidemiology of periodontal disease and cardiovascular disease. J Periodontol 2005;76(11 Suppl):2089-100.

Biasucci LM, D’Onofrio G, Liuzzo G, Zini G, Monaco C, Caligiuri G, et al. Intracellular neutrophil myeloperoxidase is reduced in unstable angina and acute myocardial infarction, but its reduction is not related to ischemia. J Am Coll Cardiol 1996;27(3):611-6.

Brasil. Ministério da Saúde. Indicadores e dados básicos - Brasil. 2005. Disponível em: URL: http://www.datasus.gov.br/idb [2008 09 08].

\footnotetext{
${ }^{1}$ De acordo com Estilo Vancouver. Abreviatura de periódicos segundo base de dados MEDLINE.
} 
Braunwald E. Shattuck lecture - cardiovascular medicine at the turn of the millennium: Triumphs, concerns, and opportunities. N Engl J Med 1997;337(19):1360-9.

Brown JL, Löe H. Prevalence, extent, severity and progression of periodontal disease. Periodontol 2000 1993;2:57-71.

Cairo F, Gaeta C, Dorigo W, Oggioni MR, Pratesi C, Pini Prato GP, et al. Periodontal pathogens in atheromatous plaque. A controlled clinical and laboratory trial. J Periodontal Res. 2004;39(6):442-6.

Carmona IT, Diz Dios P, Scully C. An update on the controversies in bacterial endocarditis of oral origin. Oral Surg Oral Med Oral Pathol Oral Radiol Endod 2002;93(6):660-70.

Chen LP, Chiang CK, Chan CP, Hung KY, Huang CS. Does periodontitis reflect inflammation and malnutrition status in hemodialysis patients? Am J Kidney Dis 2006;47(5):815-22.

Chiu B. Multiple infections in carotid atherosclerotic plaques. Am Heart J $1999 ; 138(5): 534-6$.

Choi JI, Chung SW, Kang HS, Rhim BY, Kim SJ, Kim SJ. Establishment of porphyromonas gingivalis heat-shock-protein-especific T-cell lines from atherosclerosis patients. J Dent Res 2002;81(5):344-8.

Conner HD, Haberman S, Collings CK, Winford TE. Bacteremias following periodontal scalling in patients with healthy appeaing gingiva. J Periodontol $1967 ; 38(6): 466-72$.

Contreras A, Herrera JA, Soto JE, Arce RM, Jaramillo A, Botero JE. Periodontitis is associated with preeclampsia in pregnant women. J Periodontol 2006;77(2):182-8.

Cruz JC, Nadanovsky P. Doenças periodontais causam doenças cardiovasculares? Análise das evidências epidemiológicas. Cad Saúde Pública 2003;19(2):357-68. 
D'Aiuto F, Pakar M, Andreou G, Brett PM, Ready D, Tonetti MS. Periodontitis and atherogenesis: causal association or simple coincidence? J Clin Periodontol 2004;31(5):402-11.

Dasanayake AP, Boyd D, Madianos PN, Offenbacher S, Hills E. The association between Porphyromonas gingivalis-specific maternal serum IgG and low birth weight. J Periodontol 2001;72(11):1491-7.

De Servi S, Ricevuti G, Mazzone A, Ghio S, Zito A, Raffaghello S, et al. Granulocyte function in coronary artery disease. Am J Cardiol 1991;68(7):64B68B.

Deshpande RG, Khan MB, Genco CA. Invasion of aortic and heart endothelial cells by Porphyromonas gingivalis. Infect Immun 1998;66(11):5337-43.

DeStefano F, Anda RF, Kahn HS, Williamson DF, Russell CM. Dental disease and risk of coronary heart disease and mortality. BMJ 1993;306(6879):688-91.

Desvarieux M, Demmer RT, Rundek T, Boden-Albala B, Jacobs DR Jr, Sacco $\mathrm{RL}$, et al. Periodontal Microbiota and Carotid Intima-Media thickness: The Oral Infections and Vascular Disease Epidemiology Study (INVEST). Circulation 2005;111(5):576-82.

Dias LZS. Doença periodontal como fator de risco para a doença cardiovascular. [Tese de Doutorado]. São Paulo: Faculdade de Odontologia da UFRJ; 2002.

Dogan B, Buduneli E, Emingil G, Atilla G, Akilli A, Antinheimo J, et al. Characteristics of periodontal microflora in acute myocardial infarction. $\mathrm{J}$ Periodontol 2005;76(5):740-8.

Dorn BR, Dunn WA Jr, Progluske-Fox A. Invasion of human coronary artery cells by periodontal pathogens. Infect Immun 1999;67(11):5792-8.

Elkaïm R, Dahan M, Kocgozlu L, Werner S, Kanter D, Kretz JG, et al. Prevalence of periodontal pathogens in subgingival lesions, atherosclerotic plaques and healthy blood vessels: a preliminary study. J Periodont Res 2008;43(2):224-31. 
Epstein SE, Zhou YF, Zhu J. Infections and atherosclerosis: emerging mechanistic paradigms. Circulation 1999;100(4):20-8.

Fiehn NE, Larsen T, Christiansen N, Holmstrup P, Schroeder TV. Identification of periodontol pathogens in atherosclerotic vessels. J Periodontol 2005;76(5):731-6.

Figueredo CM, Gustafsson A, Asman B, Bergtrom K. Increased release of elastase from in vitro activated peripheral neutrophils in patients with adult periodontitis. J Clin Periodontol 1999;26(4):206-11.

Fischer RG. Doença Periodontal e Doenças Cardiovasculares? In: Paiva JS, Almeida RV. Periodontia: a atuação clínica baseada em evidências científicas. 1a. São Paulo: Artes Médicas; 2005. cap. 18, p. 285-94.

Fox $\mathrm{CH}$. New considerations in the prevalence of periodontal disease. Curr Opin Dent 1992;2:5-11.

Garcia RI, Henshaw MM, Krall EA. Relationship between periodontal disease and systemic health. Periodontol 2000 2001;25:21-36.

Genco RJ. Cardiovascular disease and oral infections. In:AUTOR DO LIVRO. Periodontal medicine. Ontário: BC Decker; 2000. p. 63-82.

Gustafsson A, Asman B. Increased release of free oxygen radicals from peripheral neutrophils in adult periodontitis after Fc delta-receptor atimulation. $\mathrm{J}$ Clin Periodontol 1996;23(1):38-44.

Guyton AC. O músculo cardíaco: o coração como bomba. In: Guyton AC. Tratado de fisiologia médica. $8^{\underline{a}}$ ed. Rio de Janeiro: Guanabara Koogan; 1992. p. 99-104.

Haffajee AD, Socransky SS. Microbial etiological agents of destructive periodontal diseases. Periodontol 2000 1994;5:78-111.

Haynes WG, Stanford C. Periodontal disease and atherosclerosis: From dental to arterial plaque. Arterioscler Thromb Vasc Biol 2003;23(8):1309-11. 
Haraszthy VI, Zambon JJ, Trevisan M, Zeid M, Genco RJ. Identification of periodontal pathogens in atheromatous plaques. J Periodontol 2000;71:155460.

Haraszthy VI. Periodontal pathogens in atheromas from german population. Ann Periodontol 2001; 6(1):64.

Hasegawa K, Furuichi Y, Shimotsu A, Nakamura M, Yoshinaga M, Kamitomo $\mathrm{M}$, et al. Associations between systemic status, periodontal status, serum cytokine levels, and delivery outcomes is pregnant women with a diagnosis of threatened premature labor. J Periodontal 2003;74(12):1764-70.

Herzberg MC, Meyer MW. Effects of oral flora on platelets: Possible consequences in cardiovascular disease. J Periodontol1996,67(10 Suppl):113842.

Hujoel PP, Drangsholt M, Spiekerman C, DeRouen TA. Examining the link between coronary heart disease and the elimination of chronic dental infections. J Am Dent Assoc 2001;132(7):883-9.

Hujoel PP, Drangsholt M, Spiekerman C, DeRouen TA. Periodontal disease and coronary heart disease risk. J Am Med Assoc 2000; 284(11):1406-10.

Hujoel PP, Drangsholt M, Spiekerman C, DeRouen TA. Pre-existing cardiovascular disease and periodontitis: a follow-up study. J Dent Res 2002;81(3):186-91.

Isola J, DeVries S, Chu L, Ghazvini S, Waldman F. Analysis of changes in DNA sequence copy number by comparative genomic hybridization in archival paraffin-embedded tumor samples. Am J Pathol 1994;145(6):1301-8.

Ishihara K, Nabuchi A, Ito R, Miyachi K, Kuramitsu HK, Okuda K. Correlation between detection rates of periodontopathic bacterial DNA in coronary stenotic artery plaque and in dental plaque samples. J Clin Microbiol 2004;42(3):1313-5.

Joshipura KJ, Hung HC, Rimm EB, Willett WC, Ascherio A. Periodontal disease, tooth loss, and incidence of ischemic stroke. Stroke 2003;34(1):47-52. 
Kai H, Ikeda H, Yasukawa A, Kai M, Seki Y, Kuwahara F, et al. Peripheral blood levels of matrix metalloproteinases- 2 and 9 are elevated in patients with acute coronary syndromes. J Am Coll Cardiol 1998;32(2):368-72.

Khader YS, Albashaireh ZSM, Alomari MA. Periodontal diseases and risk of coronary hearth and cerebrovascular diseases: a meta-analysis. J Periodontol 2004;75(8):1046-53.

Kinane DF, Lowe GD. How periodontal disease may contribute to cardiovascular disease. Periodontol 2000 2000;23:121-6.

Kollveit KM, Eriksen HM. Is the observed association between periodontitis and atherosclerosis causal? Eur J Oral Sci 2001;109(1):2-7

Kozarov E, Sweier D, Shelburne C, Progulske-Fox A, Lopatin D. Detection of bacterial DNA in atheromathous plaques by quantitative PCR. Microbes Infect 2006;8(3):687-93.

Lafaurie GI, Mayorga-Fayad I, Torres MF, Castillo DM, Aya MR, Barón A, et al. Periodontopathic microorganisms in peripheric blood after scaling and root planning. J Clin Periodontol 2007;34(10):873-9.

Lalla E, Kaplan S, Chang SJ, Roth GA, Celenti R, Hinckley K, et al. Periodontal infection profiles in type 1 diabetes. J Clin Periodontol 2006;33(12):855-62.

Lalla E, Lamster IB, Hofmann MA, Bucciarelli L, Jerud AP, Tucker S, et al. Oral infection with a periodontal pathogen accelerates early atherosclerosis in apolipoprotein E-null mice. Arterioscler Thromb Vasc Biol 2003;23(8):1405-11.

Li L, Messas E, Batista EL Jr, Levine RA, Amar S. Porphyromonas gingivalis infection accelerates the progression of atherosclerosis in a heterozygous apolipoprotein E-deficient murine model. Circulation 2002; 105(7):861-7.

Lindsberg PJ, Grau AJ. Inflammation and infections as risk factors for ischemic stroke. Stroke 2003;34:2518-32.

Lin D, Moss K, Beck JD, Hefti A, Offenbacher S. Persistentlty high levels of periodontal pathogens associated with preterm pregnancy outcome. J Periodontol 2007;78(5):833-41. 
Loesche WJ. DNA probe and enzyme analysis in periodontal diagnostics. J Periodontol 1992;63(12):1102-9.

Loos BG, Craandijk J, Hoek FJ, Wertheim-van Dillen PM, van der Velden U. Elevation of systemic markers related to cardiovascular diseases in the peripheral blood of periodontitis patients. J Periodontol 2000;71(10):1528-34.

Mackenzie RS, Millard HD. Interrelated effects of diabetes, artherosclerosis and calculus on alveolar bone loss. JADA 1963; 66:191-9.

Mattila KJ, Nieminen MS, Valtonen VV, Rasi VP, Kesäniemi YA, Syrjälä SL, et al. Association between dental health and acute myocardial infarction. BMJ $1989 ; 298(6676): 779-82$.

Mattila KJ, Valle MS, Nieminen MS, Valtonen VV, Hietaniemi KL. Dental infections and coronary atheroclerosis. Atherosclerosis 1993;103(2):205-11.

Mattila KJ, Valtonen VV, Nieminem MS, Huttunen JK. Dental infections and the risck of new coronary events: prospective study of patients with documented coronary heart disease. Clin Infect Dis 1995;20(3):588-92.

Mendall MA, Patel P, Asante M, Ballam L, Morris J, Strachan DP, et al. Relation of serum cytokine concentrations to cardiovascular risk factors and coronary heart disease. Heart 1997;78(3):273-7.

Nakib SA, Pankow JS, Beck JD, Offenbacher S, Evans GW, Desvarieux M, et al. Periodontitis and coronary artery calcification: the atherosclerosis risk in communities (ARIC) study. J Periodontol 2004;75(4):505-10.

Okuda K, Ishihara K, Nakagawa T, Hirayama A, Inayama Y. Detection of Treponema denticola in atherosclerotic lesions. J Clin Microbiol $2001 ; 39(3): 1114-7$.

Overholser CD, Moreillon P, Glauser MP. Experimental bacterial endocarditis after dental extractions in rats with periodontitis. J Infect Dis. 1987;155(1):10712.

Overholser CD, Moreillon P, Glauser MP. Experimental endocarditis following dental extractions in rats with periodontitis. J Oral Maxillofac Surg 1988;46(10):857-61. 
Padilla C, Lobos O, Hubert E, Gonzalez C, Matus S, Pereira M, et al.

Periodontol pathegens in atheromatous plaque isolated from patients with chronic periodontitis. J Periodontal Res 2006;41(4):350-3.

Page RC. The pathobiology of periodontal diseases may affect systemic diseases: inversion of a paradigm. Ann Periodontol 1998;3(1):108-20.

Paquette DW, Brodala N, Nichols TC. Cardiovascular disease, inflammation, and periodontal infection. Periodontol 2000 2007;44:113-26.

Paraskevas S, Huizinga JD, Loos BG. A systematic review and meta-analyses on $\mathrm{C}$-reactive protein in relation to periodontitis. J Clin Periodontol 2008;35(4):277-90.

Pucar A, Milasin J, Lekovic V, Vukadinovic M, Ristic M, Putnik S, et al. Correlation between atherosclerosis and periodontal putative pathogenic bacterial infections in coronary and internal mammary arteries. J Periodontol 2007;78(4):677-82.

Pupim LB, Caglar K, Hakim RM, Shyr Y, Ikizler TA. Uremic malnutrition is a predictor of death independent of inflammatory status. Kidney Int $2004 ; 66(5): 2054-60$.

Pussinen PJ, Mattila K. Periodontal infections and atherosclerosis: mere associations? Curr Opin Lipidol 2004;15(5):583-8.

Rahmati MA, Craig RG, Homel P, Kaysen GA, Levin NW. Serum markers of periodontal disease status and inflammation in hemodialysis patients. Am J Kidney Dis 2002;40(5):983-9.

Romano F, Barbui A, Aimetti M. Periodontal pathogens in periodontal pockets and in carotid atheromatous plaque. Minerva Stomatol 2007;56(4):169-79.

Ross R. Atherosclerosis: an inflammatory disease. N Engl J Med $1999 ; 340(2): 115-26$.

Ross R. The pathogenis of atherosclerosis. An update. N Engl J Med 1986;314:488-500. 
Ross R, Glomset JA. The pathogenis of atherosclerosis. N Engl J Med 1976;295:369.

Scannapieco FA. Position paper of The American Academy of Periodontology: periodontal disease as a potential risk factor for systemic diseases. J Periodontol 1998;69(7):841-50.

Sims TJ, Lernmark A, Mancl LA, Schifferle RE, Page RC, Persson GR. Serum IgG to heat shock proteins and Porphyromonas gingivalis antigens in diabetic patients with periodontitis. J Clin Periodontol 2002;29(6):551-62.

Slots J. Casual or causal relationship between periodontal infection and nonoral disease? J Dent Res 1998;77(10):1764-5.

Socransky SS, Haffajee AD, Cuginl MA, Smith C, Kent RL Jr. Microbial complexes in subgingival plaque. J Clin Periodontol 1998;25(2):134-44.

Socransky SS, Smith C, Haffajee AD. Subgingival microbial profiles in refractory periodontal disease. J Clin Periodontol 2002;29(3):260-8.

Souza AGMR, Staico R, Souza JEMR. Revascularização miocárdica percutânea: dos balões ao stents farmacológicos. Stent Coronário: aplicações clínicas. São Paulo: Atheneu; 2001. p. 1-10.

Stelzel M, Stelzel M, Conrads G, Pankuweit S, Maisch B, Vogt S, et al. Detection of prophyromonas gingivalis DNA in aortic tissue by PCR. J Periodontol 2002;73(8):868-70.

Taylor-Robinson D, Aduse-Opoku J, Sayer P, Thomas BJ, Curtis MA. Orodental bacteria in various atherosclerotic arteries. Eur $\mathrm{J}$ Clin Microbiol Infect Dis 2002;21(10):755-7.

Toledo BEC, Rossa Junior C. Influência das condições sistêmicas sobre as doenças periodontais e das doenças periodontais sobre as condições sistêmicas. In: Tunes UR, Rapp GE, coordenador. Atualização em periodontia e implantodontia. 3를. ed. São Paulo: Artes Médicas; 1999. p. 30-60.

Tonetti MS, Claffey N. Advances in the progression of periodontitis and proposal of definitions of a periodontitis case and disease progression for use in risk factor research. J Clin Periodontol 2005;32 Suppl 6:210-3. 
Valle PV, Baptista EM. Doenças da aorta. In: Valle PV, Baptista EM.

Hemodinâmica e angiografia. São Paulo: Atheneu; 1996. p. 585-614.

Wahlfors J, Meurman JH, Väisänen P, Alakuijala P, Korhonen A, Torkko H, Jänne J. Simultaneous detection of Actinobacillus astinomycetemcomitans and Porphyromonas gingivalis by a rapid PCR method. J Dent Res 1995;74(11):1796-801.

Zambor JJ, Haraszthy VI. The laboratory diagnosis of periodontal infections. Periodontol 2000 1995;7(1):69-82. 


\section{Faculdade de Odontologia}

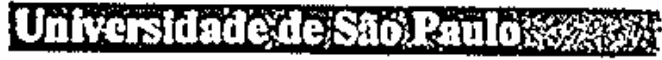

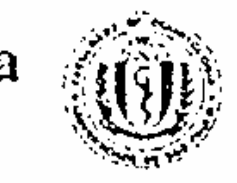

CEPIOF.270/02

Saco Paulo, 11 de outubro de 2002

Senhor Pesquisador

Infomamos a Vossa Senhoria, que diante do Parecer de Aprovaçäo do Comite de Etica do Hospital Evangèlico da Sociedade Evangélita Beneficente de Londrina, estamos cientes da aprovaço do projeto de pesquisa intitulado "Avaliaçáo microblológica da presonça do porlodontopatogonos em arterioma de paclentes submotjos a endarterectomla coronarlana o sua rolaçāo com a condiçso clinlca periodontal" de sua autoria, năo havendo nenhuma oposiçăo por parte deste CEP, com relaçăo a sua realizaçăo.

Sendo o que se nos apresentava, valemo-nos da oportunidade para reiterar-the os nossos proteslos de elevada estima e distinta consideraça.

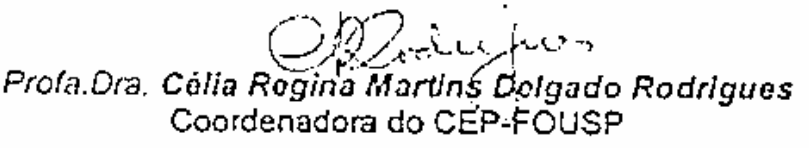

t)ustrissimo Senhor

Professor Doutor Giuseppe Alcxandre Romito

Disciplina de Periodontia 